\title{
Microvascular Complications of Type 1 Diabetes Mellitus Screening in Children, Adolescents and Young Adults: Report from a Small Center in a Limited Resource Setting, Brazzaville - Congo
}

\author{
Missambou Mandilou SV ${ }^{1,2 *}$ É Bouénizabila ${ }^{2,3}$, F Nganga Ngabou 4 , LC Ollandzobo Ikobo ${ }^{1}$, JR Mabiala \\ Babela $^{1}$, T Ngwiri ${ }^{5}$, F De Villiers ${ }^{6}$ and F Chiarelli ${ }^{7}$ \\ ${ }^{1}$ Department of Pediatrics, Teaching Hospital of Brazzaville, Congo \\ ${ }^{2}$ The Institute of Diabetes, "Maison Bleue " of Brazzaville, Congo \\ ${ }^{3}$ Department of Metabolic and Endocrine Diseases, Teaching Hospital of Brazzaville, Congo \\ ${ }^{4}$ Department of Ophthalmology, Teaching Hospital of Brazzaville, Congo \\ ${ }^{5}$ Pediatric Endocrinology Training Center for Africa (PETCA)/Gertrude Children Hospital, Nairobi, Kenya \\ ${ }^{6}$ Department of Pediatrics, MEDUNSA Campus, Sefaco Makgatho Health Science University, Pretoria, South Africa \\ ${ }^{7}$ Department of Pediatrics, University of Chieti, Italy
}

\begin{abstract}
Objectives: The aim of this study was to assess the prevalence of microvascular complications of type 1 diabetes mellitus, to define the relationship between the disease duration and the onset of these complications among Congolese children, adolescents and young adults with type 1 diabetes mellitus.

Material and method: A clinical hospital based prospective and cross-sectional study was conducted between January and August 2015 (8 months). The research groups included sixty-two children and adolescents (aged 8 to 19 years), and young adults (aged 20 to 24-years-old) with type 1 diabetes, with disease duration more than 5 years or disease onset during puberty, followed-up at a diabetes center named "I'Institut du diabète Maison Bleue of Brazzaville - CONGO", who signed an informed consent to participate in the study. Complication screening included: Full ophthalmologic examination, microalbuminuria screening by the measurement of the albumin to creatinine $(A / C)$ ratio, and diabetic neuropathy assessment using the Michigan Neuropathy Screening Instrument (MNSI). The HbA1c test was performed twice for all patients.
\end{abstract}

Results: $64.5 \%(n=40$ ) of patients were female, aged between 8.25 and 25 years (16.84 \pm 3.88 years). The mean disease duration was $5.12 \pm 3.16$ years. Retinopathy prevalence was $6.4 \%(n=4)$, the four patients with diabetic retinopathy had disease duration more than 5 years. Microalbuminuria $(A / C$ ratio between $30 \mathrm{mg} / \mathrm{g}$ and $299 \mathrm{mg} / \mathrm{g}$ ) was detected in $21 \%(\mathrm{n}=13)$ and $14.5 \%(n=9)$ were at risk of developing microalbuminuria ( $\mathrm{A} / \mathrm{C}$ ratio between $20 \mathrm{mg} / \mathrm{g}$ and $29 \mathrm{mg} / \mathrm{g}$ ). There was a statistically significant association between the $\mathrm{HbA1c}$ level and the presence of microalbuminuria for the 2 tests done $(p<0.05$ for both). The prevalence of diabetic neuropathy (MNSI score $\geq$ 2.5) was $1.6 \%(n=1)$. Glycemic control: $12.9 \%$ for the first $\mathrm{HbA} 1 \mathrm{c}$ and $14.5 \%$ for the second $\mathrm{HbA1C}$ of patients met the optimal control target as set by the ISPAD ( $\mathrm{HbA} 1 \mathrm{C}<7.5 \%$ or $<58 \mathrm{mmol}$ ) $\mathrm{mol})$. All the patients were on either premixed insulin alone or premixed plus regular insulin.

Conclusions: The high prevalence of microalbuminuria and the poor glycemic control found in this study among children, adolescents and young adults with type 1 diabetes followed-up at Brazzaville suggest that diabetes care with all its components need to be improved.

\section{Keywords}

Type 1 diabetes mellitus, Microvascular complications, Brazzaville - Congo

\section{Introduction}

Microvascular complications of type 1 diabetes mellitus (T1DM) include nephropathy, retinopathy and neuropathy.

*Corresponding author: Dr. Steve Vassili Missambou Mandilou, Pédiatre - Endocrinologue, Service de Pédiatrie Nourrissons, CHU de Brazzaville 13, Avenue Auxence IKONGA, BP: 32, Brazzaville, Congo, Tel: +242066546847

Accepted: March 14, 2020

Published online: March 16, 2020

Citation: Missambou MSV, Bouénizabila E, Ngabou FN, Ikobo LCO, Babela JRM, et al. (2020) Microvascular Complications of Type 1 Diabetes Mellitus Screening in Children, Adolescents and Young Adults: Report from a Small Center in a Limited Resource Setting, Brazzaville - Congo. Ann Endocrinol Metab 3(1):43-49 
Citation: Missambou MSV, Bouénizabila E, Ngabou FN, Ikobo LCO, Babela JRM, et al. (2020) Microvascular Complications of Type 1 Diabetes Mellitus Screening in Children, Adolescents and Young Adults: Report from a Small Center in a Limited Resource Setting, Brazzaville - Congo. Ann Endocrinol Metab 3(1):43-49

Clinically evident diabetes-related vascular complications are rare in childhood and adolescence. However, early functional and structural abnormalities may be present a few years after the onset of the disease and often progress during puberty [1]. These vascular changes include basement membrane thickening and mesangial expansion, and are predictive of subsequent albuminuria [2], which may further progress to overt proteinuria (macroalbuminuria) and, without any treatment, to end-stage renal disease (ESRD) [3]. Non-proliferative retinopathy is characterized by microaneurysms, retinal hemorrhages both pre- and intraretinal, cotton wool spots related to ischemia and microinfarction, hard exudates due to protein and lipid leakage, intraretinal microvascular abnormalities (IRMAs), and venular dilatation and tortuosity. Mild and moderate stages of non-proliferative retinopathy are not vision-threatening and do not invariably progress to more severe stages of retinopathy [4]. More severe lesions are seen in severe non-proliferative retinopathy (vascular obstruction, increase in number of retinal hemorrhages and microaneurysms, IRMAs, marked venous abnormalities, and ischemia and infarctions of the retinal nerve fibers causing cotton wool spots) and in proliferative diabetic retinopathy (neovascularisation in the retina and/or vitreous posterior surface, ruptured vessels or bleeding into the vitreoretinal space which is vision threatening) [1].

Vascular complications of T1DM are triggered by chronic hyperglycemia - the main cause - accompanied by non-specific risk factors, either associated with diabetes or independent of it, as well as by a very likely genetic predisposition, which has not been sufficiently elucidated yet [5]; Longer duration of diabetes, older age and puberty are part of them [1]. T1DM in children and adolescents has a much more severe evolution and faster development [6]. The quality of life of patients with T1DM diagnosed during childhood depends on the proper diagnosis, treatment and prevention of complications. Therefore, childhood and adolescence is a period during which intensive education and treatment may prevent or delay the onset and progression of complications in later adult life [7]. There has been a declining incidence of complications reported in many areas with specialized clinics $[8,9]$. This has occurred over a period of time during which there have been major changes in diabetes management, identification of putative risk factors, and the advent of regular screening for complications. There is no evidence that this is a world-wide occurrence: In areas where health care is not optimal, a greater risk of complications will remain. Information on chronic complications of diabetes in sub-Saharan Africa is scarce; however, its incidence has gone hand in hand with the growing disease prevalence, demonstrating the importance of assessing complications. The few studies on chronic complications of diabetes in Africa have shown a high prevalence of both acute and chronic complications [10-12]. The importance of tight glycemic control to mitigate these effects has been confirmed in large prospective studies [7,13]. For these reasons, the pediatric years present a key opportunity for early detection of these processes and for interventions that would prevent or minimize future morbidity.
The aim of the study is to screen the microvascular complications, to define the relationship between the duration of diabetes and the onset of complications in Congolese children, adolescents and young adults with T1DM.

\section{Material and Methods}

The study was a clinical hospital based prospective and cross-sectional study carried out at I'Institut du diabète "Maison Bleue" in Brazzaville, Republic of Congo. This is a Non-Governmental Organization (NGO), the only existing center providing ambulatory diabetes care to children and adolescents with diabetes in Brazzaville and its surrounding area. The study was conducted between January and August 2015 (8 months). The research groups included children and adolescents (aged 8 to 19 years), and young adults (aged 20 to 25 years old) with T1DM followed-up at the center; patients with disease duration above 5 years or disease onset during puberty, signed themselves an informed consent (for those aged 18 years and above) or signed by their parents/ guardians for those below 18 years. Microvascular complications screening consisted of diabetic neuropathy assessment, a full ophthalmologic examination, and microalbuminuria screening.

Sociodemographic data, especially those relating to age of the patient, level of education of both the patient and the parent/guardian, the socioeconomic status of the family (obtained by using Gayral-Taminh classification [14]) were obtained by using a structured questionnaire. A complete medical history was obtained and a comprehensive physical examination undertaken. Height was determined with a rigid stadiometer against a vertical wall and weight measured using an electronic scale. Body mass index (BMI) was calculated according to the Quetelet equation (Weight $(\mathrm{kg}) /$ Height $\left(\mathrm{m}^{2}\right)$ ). For children and adolescents aged 20 years and below, the BMI for age weight status based on Center for Disease Control (CDC) BMI for age was used for interpreting results and for those above 20 years old the World Health Organization (WHO) International classification [15] of adult patients according to BMI was used. A sexual maturity rating was assessed using Tanner stage $[16,17]$. Diabetes neuropathy was assessed using the Michigan Neuropathy Screening Instrument (MNSI) [18]. The classification of patients after a full ophthalmologic examination was based on the International Clinical Diabetic Retinopathy and Diabetic Macular Edema Disease Severity Scales [19] and a new grading system color fundus photographs for diabetic retinopathy (DR) as proposed by Lecleire-Collet A, et al. [20]. Screening of microalbuminuria was performed by the measurement of the albumin to creatinine $(A / C)$ ratio in at least 2 spot urine specimens collected over a period of 6 months by the DCA ${ }^{\mathrm{TM}}$ Microalbumin/ Creatinine assay and after excluded a urinary infection. Ratios between $30 \mathrm{mg} / \mathrm{g}$ and $299 \mathrm{mg} / \mathrm{g}$ were defined as microalbuminuria and that equal to $300 \mathrm{mg} / \mathrm{g}$ or greater as macroalbuminuria (or clinical albuminuria), and those between $20 \mathrm{mg} / \mathrm{g}$ and $29 \mathrm{mg} / \mathrm{g}$ as being at risk of developing microalbuminuria; To be considered as positive, two of three specimens collected within a period of 3 to 6 months had to be abnormal [21].

Two tests of glycosylated hemoglobin (HbA1c) were per- 
Citation: Missambou MSV, Bouénizabila E, Ngabou FN, Ikobo LCO, Babela JRM, et al. (2020) Microvascular Complications of Type 1 Diabetes Mellitus Screening in Children, Adolescents and Young Adults: Report from a Small Center in a Limited Resource Setting, Brazzaville - Congo. Ann Endocrinol Metab 3(1):43-49

formed for all patients (the first one in January and the second in June), using a 'DCA 2000 advantage' assay. As results are expressed in percentages, the maximum read being $14 \%$ $(130 \mathrm{mmol} / \mathrm{mol})$, to allow means and SD calculations every result equal or above $14 \%$ was considered as $14 \%(130 \mathrm{mmol})$ $\mathrm{mol})$. Patients were categorized according to the DCCT standardized classification as follow: optimal control: HbA1c < $7.5 \%$ (< $58 \mathrm{mmol} / \mathrm{mol})$; suboptimal control: $\mathrm{HbA1c} 7.5 \%$ to $\leq$ $9 \%(58 \mathrm{mmol} / \mathrm{mol}$ to $75 \mathrm{mmol} / \mathrm{mol}) ;$ and high risk: $\mathrm{HbA1c}>$ $9 \%$ (> $75 \mathrm{mmol} / \mathrm{mol}$ ) [22].

The study received an approval from the National Health

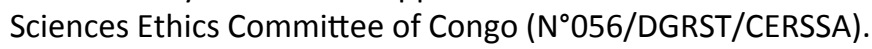
Statistical analysis was performed using Epi Info software version 3.5.1. The quantitative variables were expressed as means and the qualitative variables in percentages. Fisher and the Kruskal-Wallis $\mathrm{H}$ tests were used to compare subgroups of patients and a p-value of $\leq 0.05$ was regarded as statistically significant. The data reported as mean \pm SD for all parameters.

\section{Results}

A total of sixty-two patients were enrolled in the study, $40(64.5 \%)$ were female $(\mathrm{F})$ and $22(35.5 \%)$ were male $(\mathrm{M})$, an $\mathrm{M} / \mathrm{F}$ ratio $1: 1.8$. The age of the participants ranged between 8.25 and 25 years $(16.84 \pm 3.88)$. Thirty-one patients had a disease duration below or equal to 5 years $(50 \%)$ and the remaining thirty-one a disease duration more than 5 years. The mean disease duration was $5.12 \pm 3.16$ years; the shortest du- ration was one year and the longest thirteen years. Regarding the glycemic control for the first HbA1c, forty-five patients $(72.6 \%)$ were classified as high risk, nine patients $(14.5 \%)$ had suboptimal control and eight (12.9\%) had optimal control. For the second test, forty-two patients $(67.8 \%)$ had high risk, eleven patients $(17.7 \%)$ had suboptimal control and nine (14.5\%) had optimal control. The mean of $\mathrm{HbA1c}$ was respectively $10.80 \pm 2.80 \%[5.5 \% ;>14 \%](95 \mathrm{mmol} / \mathrm{mol} \pm 9$ [37; > $130]$ ) and $10.62 \pm 2.87 \%$ [5.1\%; $>14 \%]$ for the first and the second tests; $p$-value $>0.5$. Four patients $(6.4 \%)$ out of the sixty-two had diabetic retinopathy $(92 \mathrm{mmol} / \mathrm{mol} \pm 9[32 ;>$ 130] (Table 1), thirteen (21\%) had positive microalbuminuria, nine $(14.5 \%)$ were at risk of developing microalbuminuria and in forty $(64.5 \%)$ patients the two microalbuminuria screening tests performed were negative. None of the patients was found to have clinical albuminuria or overt macroalbuminuria; there was no association $(p<0.05)$ between disease duration and microalbuminuria (Table 2). One patient (1.6\%) had diabetic neuropathy (a total Michigan Neuropathy Screening Instrument score $\geq 2.5$ ), was a male aged 20 years and 7 months with a disease duration equal to 7 years, of a low socioeconomic status, was underweight and was at high risk concerning both $\mathrm{HbA1c}$ tests. All patients were on conventional therapy ( 2 injections per day of premixed insulin 70/30 alone or 2 injections of premixed insulin plus 1 injection of regular insulin per day). The premixed insulin profile was the 70/30. All patients are part of "Life for a child" program, meaning that the program provide for all of them free insulin, some receive fifty strips per month for blood glucose monitoring.

Table 1: Correlation between variables and ophthalmologic examination findings.

\begin{tabular}{|c|c|c|c|c|}
\hline & & \multicolumn{2}{|c|}{ Diabetic retinopathy } & \multirow[b]{2}{*}{ p-value } \\
\hline & & Absent $(n=58)$ & Present $(n=4)$ & \\
\hline \multirow[b]{2}{*}{ Gender } & Male n (\%) & $21(36.2 \%)$ & $1(25 \%)$ & \multirow[t]{2}{*}{0.6} \\
\hline & Female $\mathrm{n}(\%)$ & $37(63.8 \%)$ & $3(75 \%)$ & \\
\hline \multirow[t]{2}{*}{ Disease duration } & $\leq 5$ years $n(\%)$ & $31(53.4 \%)$ & 0 & \multirow[t]{2}{*}{0.056} \\
\hline & $>5$ years $n(\%)$ & $27(46.6 \%)$ & $4(100 \%)$ & \\
\hline \multirow[t]{3}{*}{ Socioeconomic status } & High n (\%) & $11(19 \%)$ & 0 & \multirow{3}{*}{0.4} \\
\hline & Middle n (\%) & $28(48.3 \%)$ & $2(50 \%)$ & \\
\hline & Low n (\%) & $19(32.7 \%)$ & $2(50 \%)$ & \\
\hline \multirow[t]{3}{*}{ SMR (Tanner) } & Prepubertal n (\%) & $3(5.2 \%)$ & 0 & \multirow{3}{*}{0.6} \\
\hline & Pubertal n (\%) & 24 (41.4\%) & $1(25 \%)$ & \\
\hline & Adult n (\%) & $31(53.4 \%)$ & $3(75 \%)$ & \\
\hline \multirow[t]{4}{*}{ BMI } & Normal n (\%) & $42(72.4 \%)$ & 4 & \multirow{4}{*}{0.7} \\
\hline & Underweight n (\%) & $12(20.7 \%)$ & 0 & \\
\hline & Overweight n (\%) & $4(6.9 \%)$ & 0 & \\
\hline & Obese n (\%) & 0 & 0 & \\
\hline \multirow[t]{3}{*}{ HbA1c-I } & High risk n (\%) & $42(72.4 \%)$ & $3(75 \%)$ & \multirow{3}{*}{0.7} \\
\hline & Suboptimal n (\%) & $8(13.8 \%)$ & $1(25 \%)$ & \\
\hline & Optimal n (\%) & $8(13.8 \%)$ & 0 & \\
\hline \multirow[t]{3}{*}{ HbA1c-II } & High risk n (\%) & $39(67.2 \%)$ & $3(75 \%)$ & \multirow{3}{*}{0.6} \\
\hline & Suboptimal n (\%) & $10(17.2 \%)$ & $1(25 \%)$ & \\
\hline & Optimal n (\%) & $9(15.6 \%)$ & 0 & \\
\hline
\end{tabular}


Citation: Missambou MSV, Bouénizabila E, Ngabou FN, Ikobo LCO, Babela JRM, et al. (2020) Microvascular Complications of Type 1 Diabetes Mellitus Screening in Children, Adolescents and Young Adults: Report from a Small Center in a Limited Resource Setting, Brazzaville - Congo. Ann Endocrinol Metab 3(1):43-49

Table 2: Correlation between other variables and microalbuminuria.

\begin{tabular}{|c|c|c|c|c|c|}
\hline & & \multicolumn{3}{|l|}{ Microalbuminuria } & \multirow[b]{2}{*}{ p-value } \\
\hline & & Negative $(n=40)$ & Positive $(n=13)$ & At risk $(n=9)$ & \\
\hline \multirow[b]{2}{*}{ Gender } & Male n (\%) & $16(40)$ & $5(38.5)$ & $1(11.1)$ & \multirow[t]{2}{*}{0.23} \\
\hline & Female n (\%) & $24(60)$ & $8(61.5)$ & $8(88.9)$ & \\
\hline \multirow[t]{2}{*}{ Disease duration } & $\leq 5$ years $\mathrm{n}(\%)$ & $19(47.5)$ & $5(38.5)$ & $7(77.8)$ & \multirow[t]{2}{*}{0.26} \\
\hline & $>5$ years $n(\%)$ & $21(52.5)$ & $8(61.5)$ & $2(22.2)$ & \\
\hline \multirow[t]{3}{*}{ Socioeconomic status } & High n (\%) & $6(15)$ & $3(23.1)$ & $2(22.2)$ & \multirow{3}{*}{0.27} \\
\hline & Middle n (\%) & $19(47.5)$ & $7(53.8)$ & 4 (44.5) & \\
\hline & Low n (\%) & $15(37.5)$ & $3(23.1)$ & $3(33.3)$ & \\
\hline \multirow[t]{3}{*}{ SMR (Tanner) } & Prepubertal n (\%) & $1(2.5)$ & $1(7.7)$ & $1(11.1)$ & \multirow{3}{*}{0.51} \\
\hline & Pubertal n (\%) & $18(45)$ & $2(15.4)$ & $5(55.6)$ & \\
\hline & Adult n (\%) & $21(52.5)$ & $10(76.9)$ & $3(33.3)$ & \\
\hline \multirow[t]{4}{*}{ BMI } & Normal n (\%) & $29(72.5)$ & 10 (76.9) & $7(77.8)$ & \multirow{4}{*}{0.43} \\
\hline & Underweight n (\%) & $8(20)$ & $3(23.1)$ & $1(11.1)$ & \\
\hline & Overweight n (\%) & $3(7.5)$ & 0 & $1(11.1)$ & \\
\hline & Obese n (\%) & 0 & 0 & 0 & \\
\hline \multirow{3}{*}{ HbA1c-I } & High risk n (\%) & $25(62.5)$ & $13(100)$ & $7(77.8)$ & \multirow{3}{*}{0.008} \\
\hline & Suboptimal n (\%) & $8(20)$ & 0 & $1(11.1)$ & \\
\hline & Optimal n (\%) & 7 (17.5) & 0 & $1(11.1)$ & \\
\hline \multirow{3}{*}{ HbA1c-II } & High risk n (\%) & $23(57.5)$ & $12(92.3)$ & $7(77.8)$ & \multirow{3}{*}{0.02} \\
\hline & Suboptimal n (\%) & $9(22.5)$ & $1(7.7)$ & $1(11.1)$ & \\
\hline & Optimal n (\%) & $8(20)$ & 0 & $1(11.1)$ & \\
\hline
\end{tabular}

\section{Discussion}

Glycemic control was exceptionally poor in our study population. This is well documented fact in most of African settings, and especially in adolescents with type 1 diabetes mellitus. The following mean HbA1c from some studies corroborate this statement: $11.2 \pm 4.5 \%$ (99 mmol/ $\mathrm{mol} \pm 26)$ in Rwanda [23], $13.9 \%$ (128 $\mathrm{mmol} / \mathrm{mol})$ in Tanzania [24], 11.4\% (101 $\mathrm{mmol} / \mathrm{mol})$ in Nigeria [12], and an even worse in the Democratic Republic of Congo [25] where only $8 \%$ of the study population had a HbA1c below $7 \%(53 \mathrm{mmol} / \mathrm{mol})$ and in another study in Tanzania [26] where only $5 \%$ of the study population reached the target of $\mathrm{HbA1c} \leq 7.5 \%$ ( $58 \mathrm{mmol} / \mathrm{mol})$. This picture is different from northern countries (North America, Japan, Australia and Europe) where $\mathrm{HbA1c}$ are much better than those encountered in Africa [27-29]. We hypothesized that puberty, gender and insulin type could be the most reasons for this poor control. As shown in the results section, the majority of patients enrolled in this study were in pubertal stages, were females, even if no statistically significant association between the HbA1c level and the gender [p > $0.05]$ was noted. Studies have shown that glycemic control often deteriorates during adolescence period, adolescents being currently the farthest from achieving HbA1c $<7.5 \%$ $(58 \mathrm{mmol} / \mathrm{mol})$ and $\mathrm{HbA1c}$ levels may be higher than at any other time [30-33]. Patients on premixed insulin (Neutral Protamine Hagedorn and regular insulin) have been found to have poor glycemic control compared with their peers on either insulin analogs or more intensive management of diabetes including insulin pumps $[23,26,27,30,34]$.

Studies from Sub-Saharan Africa dealing with microalbuminuria in children and adolescents are rare. The prevalence of microalbuminuria (21\%) in this study was higher than the $12 \%$ in Tanzania [24]; similar to those reported in Rwanda [23] and in Congo-Kinshasa [25] (21\% and 21.9\% respectively). Therefore, this is higher than those in another Tanzanian study [11] and in Nigeria [12] (29.3\% and $33.3 \%$ respectively). Differences in methodology, age of patients and may be the definition of microalbuminuria may account for these differences. It's well known that increasing age is associated with a higher risk for the development of microalbuminuria [35-37]. On the other side, our results are far high than those found in studies done in western countries [38-40], which are known to have good health care systems, very specialized diabetes care centers and good patients' follow-up. In this study, poor glycemic control (high risk group) was found to have a statistically significant association with the presence of microalbuminuria for the two HbA1c tests done $(p<0.05)$, supporting the idea that poor glucose control increases the risk of developing microalbuminuria in youths with type 1 diabetes [40-43].

Diabetic retinopathy (DR) is rare in prepubertal children, but it is quite common in young patients with diabetes $[44,45]$ and its prevalence had been found to be high in young adults with longer disease duration $[11,46]$; it in- 
Citation: Missambou MSV, Bouénizabila E, Ngabou FN, Ikobo LCO, Babela JRM, et al. (2020) Microvascular Complications of Type 1 Diabetes Mellitus Screening in Children, Adolescents and Young Adults: Report from a Small Center in a Limited Resource Setting, Brazzaville - Congo. Ann Endocrinol Metab 3(1):43-49

creases in children with onset of the disease after puberty $[39,47,48]$. However, DR has also been described in children with short disease duration in African children [12].

There are insufficient data on the prevalence and predictors of diabetic peripheral neuropathy among the pediatric population. Furthermore, early detection and good glycemic control have been proven to prevent and delay adverse outcomes associated with diabetic polyneuropathy. Near-normal control of blood glucose, beginning as soon as possible after the onset of diabetes, may delay the development of clinically significant nerve impairment [49]. Very few studies on diabetic neuropathy in children and adolescents had been carried in African region [23,50]; though with different methods in screening neuropathy. In the literature, higher prevalence than that in this study had been reported [34,40,45,51]; Longer duration of diabetes with its sustained impact on peripheral nerves could be an important determinant of diabetic neuropathy. As mentioned early, the wide ranges in the prevalence estimates of diabetic neuropathy among the young in those different studies could be due to the differing criteria and diagnostic tests used to define and characterize diabetic neuropathy.

Although this study failed to demonstrate and to give scientific evidences of the course of these vascular complications, due to a constraint working area (lack of sophisticated diagnostic tools), this study has the merit of pointing a very crucial subject, particularly in these patients mostly from low and middle socioeconomic families. To the best of our knowledge, this is the first study which screen T1DM microvascular complications in Congolese children, adolescents and young adults with diabetes. Successful treatment of type 1 diabetes mellitus, which include improving diabetes care (availability of medical insurance for all, diabetic intensive treatment, analogs insulin, frequent blood glucose monitoring, diabetic education and psychosocial support for patients and parents/ guardians), is of particular importance for these patients to reduce, to delay or to prevent the risk of long-term vascular complications.

\section{Conclusions}

The high prevalence of early signs of microvascular complications shown in this study, mainly microalbuminuria and in a lesser proportion the presence of diabetes retinopathy in some patients shows the need for early screening of microvascular complications in children and adolescents with type 1 diabetes, especially in poor controlled patients in a constraint setting. These data show that there is a need to improve diabetes care in Congo.

\section{Acknowledgements}

A special thanks to Graham Ogle and the International Diabetes Federation (IDF), for their invaluable support with a special program "Life For a Child", along with the International Society for Pediatric and Adolescent Diabetes (ISPAD). We would like also hereby, to express our gratitude to patients and their families and to those who directly or indirectly contributed to this work.

\section{Author Contribution}

S.V.M.M. wrote/reviewed/edited the manuscript, researched data, contributed to discussion; E.B. reviewed the manuscript, researched data and contributed to discussion; F.N.N. reviewed the manuscript, L.C.O.I. contributed to discussion; J.R.M.B. reviewed/edited the manuscript and contributed to discussion; T.N. reviewed the manuscript; F.D.V. edited the first article draft, reviewed/edited the manuscript, he also contributed to discussion; F.C. contributed to discussion, reviewed/edited the manuscript.

\section{Conflict of interest}

None.

\section{Guarantor}

Dr. Steve Vassili Missambou Mandilou.

\section{References}

1. Donaghue KC, Marcovecchio ML, Wadwa RP, et al. (2018) ISPAD clinical practice consensus guidelines 2018: Microvascular and macrovascular complications in children and adolescents. Pediatr Diabetes 19: 262-274.

2. Steinke JM, Sinaiko AR, Kramer MS, et al. (2005) The early natural history of nephropathy in type 1 diabetes: III. Predictors of 5-year urinary albumin excretion rate patterns in initially normoalbuminuric patients. Diabetes 54: 2164-2171.

3. Mogensen CE, Keane WF, Bennett PH, et al. (1995) Prevention of diabetic renal disease with special reference to microalbuminuria. Lancet 346: 1080-1084.

4. Wong TY, Cheung CMG, Larsen M, et al. (2016) Diabetic retinopathy. Nat Rev Dis Primers 2: 16012.

5. Maricela Cobuz, Claudiu Cobuz (2012) Chronic complications of type 1 diabetes mellitus in children. Rom J Diabetes Nutr Metab Dis 19: 301-309.

6. Krolewski AS, Warram JH, Christlieb AR, et al. (1985) The changing natural history of nephropathy in type I diabetes. American Journal of Medicine 78: 785-794.

7. (1994) Effect of intensive diabetes treatment on the development and progression of long term complications in adolescents with insulin-dependent diabetes mellitus: Diabetes control and complications trial research group. J Pediatrics 125: 177-188.

8. Bojestig M, Arnqvist HJ, Hermansson G, et al. (1994) Declining incidence of nephropathy in insulin-dependent diabetes mellitus. N Engl J Med 330: 15-18.

9. Downie E, Craig ME, Hing S, et al. (2011) Continued reduction in the prevalence of retinopathy in adolescents with type 1 diabetes: Role of insulin therapy and glycemic control. Diabetes Care 34: 2368-2373.

10. Akanji AO (1996) Clinical experience with adolescent diabetes in a Nigerian teaching hospital. J Natl Med Assoc 88: 101-105.

11. Majaliwa ES, Munubhi E, Ramaiya K, et al. (2007) Survey on acute and chronic complications in children and adolescents with type 1 diabetes at Muhimbili National Hospital in Dar Es Salaam, Tanzania. Diabetes Care 30: 2187-2192.

12. Ogugua CF, Chikani UN, Ibekwe MU, et al. (2019) Early signs of microvascular complications in pediatric patients with short duration of type 1 diabetes mellitus seen in Southeast Nigeria. Ann Afr Med 18: 200-205. 
Citation: Missambou MSV, Bouénizabila E, Ngabou FN, Ikobo LCO, Babela JRM, et al. (2020) Microvascular Complications of Type 1 Diabetes Mellitus Screening in Children, Adolescents and Young Adults: Report from a Small Center in a Limited Resource Setting, Brazzaville - Congo. Ann Endocrinol Metab 3(1):43-49

13. Nathan DM, Lachin J, Cleary P, et al. (2003) Diabetes control and complications trial. epidemiology of diabetes interventions and complications research group. Intensive diabetes therapy and carotid intima-media thickness in type 1 diabetes mellitus. $\mathrm{N}$ Engl J Med 348: 2294-2303.

14. Gayral-Taminh M, Arnaud C, Parant O, et al. (1999) Grossesses et accouchements des femmes originaires du Maghreb et d'Afrique noire suivies à la maternité de Toulouse. J Gynécol Obstét Biol Reprod 28: 462-471.

15. (2013) World Health Organization (WHO): BMI Classifications.

16. Marshall WA, Tanner JM (1969) Variations in pattern of pubertal changes in girls. Arch Dis Child 44: 291-303.

17. Marshall WA, Tanner JM (1970) Variations in the pattern of pubertal changes in boys. Arch Dis Child 45: 13-23.

18. Herman WH, Pop-Busui R, Braffett BH, et al. (2012) Use of the Michigan neuropathy screening instrument as a measure of distal symmetrical peripheral neuropathy in type 1 diabetes: Results from the diabetes control and complications trial/epidemiology of diabetes interventions and complications. Diabet Med 29: 937-944.

19. Wilkinson CP, Ferris FL III, Klein RE, et al. (2003) Proposed international clinical diabetic retinopathy and diabetic macular edema disease severity scales. Ophthalmology 110: 1677-1682.

20. Lecleire-Collet A, Erginayb A, Angioi-Duprez K, et al. (2007) Classification simplifiée de la rétinopathie diabétique adaptée au dépistage par photographie du fond d'œil. J Fr Ophtalmol 30: 674-687.

21. American Diabetes Association (2014) Standards of medical care in diabetes. Diabetes Care 37: 44.

22. Rewers MJ, Pillay K, De Beauford C, et al. (2014) Assessment and monitoring of glycemic control in children and adolescents with diabetes. Pediatric Diabetes 15: 102-114.

23. Marshall SL, Edidin D, Sharma V, et al. (2013) Current clinical status, glucose control, and complication rates of children and youth with type 1 diabetes in Rwanda. Pediatric Diabetes 14: 217-226.

24. Lutale JJK, Thordarson H, Abbas ZG, et al. (2007) Microalbuminuria among type 1 and type 2 diabetic patients of African origin in Dar Es Salaam, Tanzania. BMC Nephrol 8: 2.

25. Makulo Rissassi JR, Nseka M, Jadoul M, et al. (2010) Prevalence and determinants of microalbuminuria and macroalbuminuria in children and young adults with type 1 diabetes in Kinshasa. Nephrol Ther 6: 40-46.

26. Mukama L, Moran A, Nyindo M, et al. (2013) Improved glycemic control and acute complications among children with type 1 diabetes mellitus in Moshi, Tanzania. Pediatric Diabetes 14: 211-216.

27. Paris CA, Imperatore G, Klingensmith G, et al. (2009) Predictors of insulin regimens and impact on outcomes in youth with type 1 diabetes: The SEARCH for diabetes in youth study. J Pediatr 155: 183-189.

28. Ziegler R, Heidtmann B, Hilgard D, et al. (2011) Frequency of SMBG correlates with $\mathrm{HbA1C}$ and acute complications in children and adolescents with type 1 diabetes. Pediatr Diabetes 12: 11-17.

29. Aanstoot HJ, Aman J, Cameron F, et al. (2007) Continuing stability of center differences in pediatric diabetes care: Do advances in diabetes treatment improve outcome? The Hvidoere study group on childhood diabetes. Diabetes Care 30: 2245-2250.

30. Mohammad HA, Farghaly HS, Metwalley KA, et al. (2012) Predictors of glycemic control in children with type 1 diabetes mellitus in Assiut-Egypt. Indian J Endocr Metab 16: 796-802.

31. Wood JR, Miller KM, Maahs DM, et al. (2013) Most youth with type 1 diabetes in the T1D Exchange Clinic Registry do not meet American Diabetes Association or International Society for Pediatric and Adolescent Diabetes clinical guidelines. Diabetes Care 36: 2035-2037.

32. Cho YH, Craig ME, Donaghue KC (2014) Puberty as an accelerator for diabetes complications. Pediatr Diabetes 15: 18-26.

33. Chowdhury S (2015) Puberty and type 1 diabetes. Indian J Endocrinol Metab 19: 51-54.

34. Jaiswal M, Lauer A, Martin CL, et al. (2013) Peripheral neuropathy in adolescents and young adults with type 1 and type 2 diabetes from the SEARCH for diabetes in Youth follow-up cohort: A pilot study. Diabetes Care 36: 3903-3908.

35. Schultz CJ, Konopelska-Bahu T, Dalton RN, et al. (1999) Microalbuminuria prevalence varies with age, sex, and puberty in children with type 1 diabetes followed from diagnosis in a longitudinal study. Diabetes Care 22: 495-502.

36. Stone ML, Craig ME, Chan AK, et al. (2006) Natural history and risk factors for microalbuminuria in adolescents with type 1 diabetes. Diabetes Care 29: 2072-2077.

37. Moayeri H, Dalili $H$ (2006) Prevalence of microalbuminuria in children and adolescents with diabetes mellitus type 1. Acta Medica Iranica 44: 105-110.

38. Lévy-Marchal C, Sahler C, Cahané M, t al. (2000) Risk factors for microalbuminuria in children and adolescents with type 1 diabetes. J Pediatr Endocrinol Metab 13: 613-620.

39. Salardi S, Porta M, Maltoni G, et al. (2012) Infant and toddler type 1 diabetes: Complications after 20 years' duration. Diabetes Care 35: 829-833.

40. Olsen BS, Sjolie A, Hougaard P, et al. (2000) A 6-year nationwide cohort study of glycaemic control in young people with type 1 diabetes: risk markers for the development of retinopathy, nephropathy and neuropathy: Danish Study Group of Diabetes in Childhood. J Diabetes Complications 14: 295-300.

41. (1995) Effect of intensive therapy on the development and progression of diabetic nephropathy in the diabetes control and complications trial. The Diabetes Control and Complications (DCCT) Research Group. Kidney Int 47: 1703-1720.

42. Cederholm J, Eliasson B, Nilsson PM, et al. (2005) Microalbuminuria and risk factors in type 1 and type 2 diabetic patients. Diabetes Res Clin Pract 67: 258-266.

43. Sivaprasad S, Gupta B, Gulliford MC, et al. (2012) Ethnic variations in the prevalence of diabetic retinopathy in people with diabetes, attending screening in the United Kingdom (DRIVE UK). PloS One 7: e32182.

44. Djonou C, Tankeu AT, Dehayem MY, et al. (2019) Glycemic control and correlates in a group of sub Saharan type 1 diabetes adolescents. BMC Res Notes 12: 50.

45. Nery Ferreira BE, Silva IN, De Oliveira JT (2005) High prevalence of diabetic polyneuropathy in a group of Brazilian children with type 1 diabetes mellitus. J Pediatr Endocrinol Metab 18: 10871094. 
Citation: Missambou MSV, Bouénizabila E, Ngabou FN, Ikobo LCO, Babela JRM, et al. (2020) Microvascular Complications of Type 1 Diabetes Mellitus Screening in Children, Adolescents and Young Adults: Report from a Small Center in a Limited Resource Setting, Brazzaville - Congo. Ann Endocrinol Metab 3(1):43-49

46. Wucher $\mathrm{H}$ et Dubois-Laforgue D (2015) Les complications microangiopathiques du diabète de type 1 chez l'adolescent et l'adulte jeune. Adolescence Médecine 9: 18-21.

47. Nordwall M, Hyllienmark L, Ludvigsson J (2006) Early diabetic complications in a population of young patients with type $1 \mathrm{dia}-$ betes mellitus despite intensive treatment. J Pediatr Endocrinol 19: 45-54.

48. Bouhanick B, Raguin H, Rohmer V, et al. (2003) Description of microangiopathy in children with type 1 diabetes mellitus: A 19year retrospective study. Diabetes Metab 29: 395-402.
49. Orchard TJ, Secrest AM, Miller RG, et al. (2010) In the absence of renal disease, 20-year mortality risk in type 1 diabetes is comparable to that of the general population: A report from the Pittsburgh epidemiology of diabetes complications study. Diabetologia 53: 2312-2319.

50. Mbanyan JC, Solongwi E (2003) Diabetes in Africa: Diabetes microvascular and macrovascular disease in Africa. J Cardiovasc Risk 10: 97-102.

51. Eppens MC, Craig ME, Cusumano J, et al. (2006) Prevalence of diabetes complications in adolescents with type 2 compared with type 1 diabetes. Diabetes Care 29: 1300-1306. 